\title{
Helminth eggs assessment of fecal sludge in urban area of Bandung, Indonesia
}

\author{
Barti Setiani Muntalif ${ }^{1}$, Mayrina Firdayati ${ }^{1}$, Febrian Dwi Lesmono ${ }^{1}$, Anya Sally Vatima Siregar $^{1}$, Peni Astrini \\ Notodarmojo $^{1}$, and Inat Shani Fathuna ${ }^{1}$ \\ ${ }^{1}$ Institut Teknologi Bandung, Environmental Engineering Departement, Indonesia
}

\begin{abstract}
Soil-transmitted helminth eggs present to be non-excludable parameter for water quality and sanitation since they are linked to public health concern. Unfortunately, investigation of helminth eggs presence in wastewater is very limited in Indonesia. The result of previous study confirmed helminth eggs presence in irrigation water and land samples in agriculture field in urban area of Bandung. Inappropriate of wastewater treatment system and reuse of unsafe wastewater are the reason why helminth egg were found in agriculture area. Therefore, this study was conducted to get better understanding of helminth eggs presence in wastewater especially in fecal sludge of the city. Samples were collected from desludging trucks servicing residential and non-residential septic tanks from total 17 areas. Modification of US EPA method is used to analyse and enumerate the viable helminth eggs. There are big variations amount of helminth egg in samples from different area, from 4 eggs/L to 617 eggs/L. We found more than 10 species of helminth eggs. Hookworm egg counts were higher than those of Fasciola hepatica and Ascaris lumbricoides. This study also showed that septic tank inefficient for reducing helminth eggs presence in fecal sludge and for fulfilled recommendation of $\mathrm{WHO}$ for safe water reuse.
\end{abstract}

\section{Introduction}

Helminth eggs cause several problem for human health. They are transmitted by eggs present in human feces, which contaminate the soil in areas where sanitation is poor. The prevalence of helminthiasis in Indonesia is still high, especially in the poor society with limited sanitation facilities and insufficient clean water [1]. Ministry of Health of the Republic of Indonesia survey stated that several provinces in Indonesia shows the prevalence of helminthiasis for all ages in Indonesia range from $40 \%-60 \%$. While the prevalence of helminthiasis in children throughout Indonesia at the age of 1-6 years or age 7-12 years at a high level, which is $30 \%$ to $90 \%$ [2]. The prevalence rate of West Java helminth infection was $6.7 \%$ [3].

Soil-transmitted helminths (STH) impair the nutritional status of the people they infect in multiple ways. People with infections of light intensity usually do not suffer from the infection. Heavier infections can cause a range of symptoms including intestinal manifestations (diarrhoea and abdominal pain), malnutrition, general malaise and weakness, and impaired growth and physical development. Infections of very high intensity can cause intestinal obstruction that should be treated surgically.

WHO estimates about 836 million children worldwide require preventive chemotherapy for soil- transmitted helminthiases. In 2016 more than 517 million children received preventive chemotherapy for STH. In 2016, 38 countries have reached the World Health Assembly's target of treating at least $75 \%$ of school-aged children for the STH disease [4].

With high prevalence of helminthiasis, Indonesia government, in 2017, has released Health Ministry of Indonesia Regulation about helminthiasis prevention [5]. The purposes of this regulation is to reduce the prevalence of helminthiasis to under $10 \%$ per city in 2019. Even sanitation and environmental management be part of effort to overcome helminthiasis but data and study about helminth eggs presence in wastewater and environment is no exist. With less coverage of sanitation infrastructure in Indonesia, dissemination of helminthiasis through their eggs is in high risk. Our previous study found helminth eggs in vegetable product, soil and water samples of urban agricultural located near the housing with poor sanitation facility around Bandung City [6]. It is important to get data and information about helminth egg presence in blackwater as main source of helminth egg before entering the domestic wastewater treatment or discharge direct to the environment especially in poor sanitation area.

Septic tank is commonly used as blackwater treatment unit. Retention time of 1-3 days for septic tank could reduce protozoa and helminths by $0-2 \log _{10}$ units [7]. Septic tank also has ability to remove STH with

\footnotetext{
* Corresponding author: mayrina@tl.itb.ac.id
} 
percentage around 99,5-100\% [8]. Prevalence of STH in desludging truck could be an indicator for sanitation quality in certain areas.

We conducted assessment on the presence of helminth eggs in wastewater in Bandung, a middle class of town in Indonesia. Assessment was done by collecting samples from desludging trucks servicing residential and non-residential septic tanks. This study reports on the presence of helminth eggs in blackwater and result identification of species which were found. The data can be used for initial description of potential risk of helminth eggs dissemination in community

\section{Materials and Method}

The samples were collected from randomly selected desludging truck that was discharging their load at Cilaki's park where there is a "manhole". It is connected to channel where sludge from septic tank will be directly flushed together to enter the Bojongsoang sewage treatment plant in the southern part of Bandung. Cilaki's park was placed in the middle of Bandung City. Samples were coming from 17 places around Bandung, that is Buah Batu, Cilaki, Cisitu, Pasteur, Setiabudi Regency, Dago Asri, Tubagus Ismail, some hotels in Pasteur area, Lembang, Leuwigajah, Cipedes, Dago Atas, Baleendah, Kiaracondong, Soreang, Antapani, and Sukajadi. The places will be divided into two categories, residential area and non-residential area. Fifty one fecal sludge samples were coming from triplo sampling from 17 places based on driver and operator interviews, Figure 1 shows the distribution area of fecal sludge collection sites.

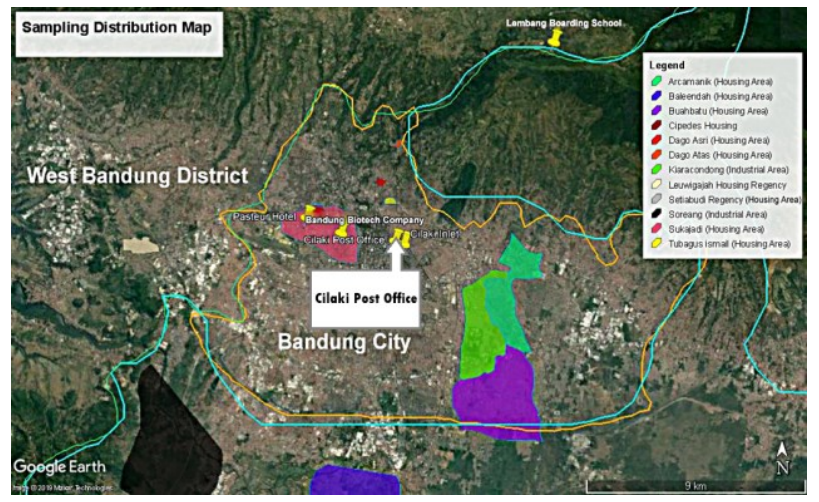

Fig. 1. Source location of sludge flushed in Cilaki

For assessment of helminth eggs, $5 \mathrm{~L}$ volumes were obtained for all samples. Differences in solid content between samples made it more feasible to test triplo sub samples of $540 \mathrm{~L}$ each.

Until now, there is no consensus with regard to the adoption of a universal methodology for the detection and quantification of viable helminth eggs [6]. We adopted USEPA method to isolate helminth eggs from fecal sludge of septic tank. Initially, 10 gram sample (dry weight) will be centrifuged for 15 minutes in $3000 \mathrm{rpm}$. $10 \mathrm{~mL} \mathrm{ZnSO}_{4}$ is added to sample in $15 \mathrm{~mL}$ centrifuge tube and centrifuge for 3 minutes after the supernatant set aside (Figure 2). Four and half $\mathrm{mL}$ acid alcohol and 3 $\mathrm{mL}$ ethyl acetate (use as rinse water) is added to the sample after set apart the supernatant phase. Sample is sentrifuged for 3 minutes after set apart the rinse water. All of supernatant is to be collected and settled overnight with $5 \mathrm{~L}$ aquadest. Sample is centrifuged for 3 minutes in $19 \mathrm{rpm} . \mathrm{H}_{2} \mathrm{SO}_{4} 0.1 \mathrm{~N}$ is added after set apart the supernatant phase, then the sample is homogenized. $\mathrm{ZnSO}_{4}$ is added to sample fourth times from sample volume. Observation and counting of helminth eggs was done by using McMaster slide. Average of amount of helminth eggs in triplo sample were used as final amount of a desludging septic tank area.

Beside presence of helminth eggs, physicochemical parameter of total solid, conductivity, $\mathrm{pH}$, BOD, orthophosphat and nitrate of residential fecal sample was analysed.

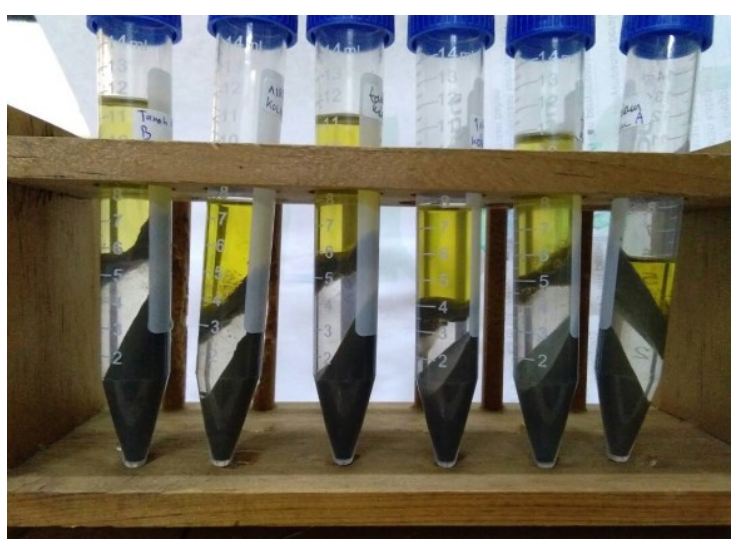

Fig. 2. Sample condition after first centrifuge

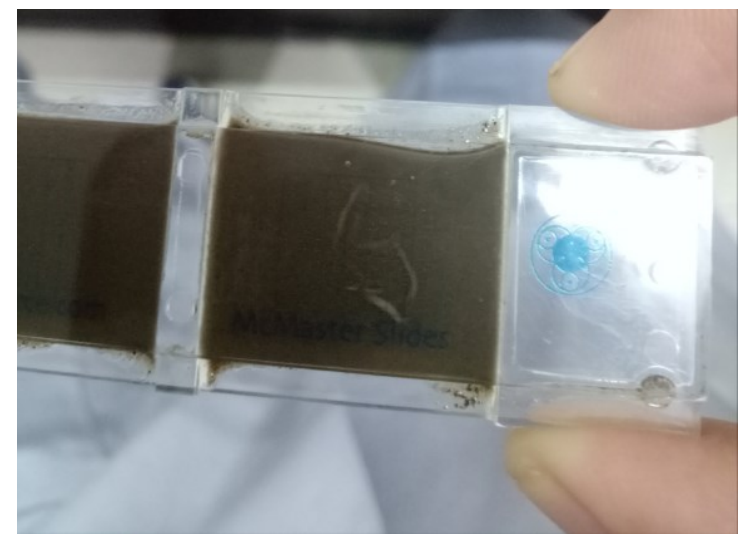

Fig. 3. Sample condition for observation using McMaster slide

\section{Results and Disscussion}

Photomicrographs of some of the helminth eggs which were found in the fecal sample tested are shown in Figure 4. Meanwhile, Figure 5 shows the percentage of helminth eggs found in the sample. The high prevalence egg of STH species found in the desludging trucks samples, namely hookworm (39\%), Ascaris lumbricoides (14\%) and parasitic trematode, Fasciola hepatica (20\%), as well as trychostrongylus (9\%), Schistosoma japonicum (5\%), Diphyllobothrium latum $(2 \%)$, and two tapeworms, Hymenolepis nana and 
H.diminuta. Species of Fasciolopsis buski, Trichuris tricuria and Clonorchis sinensis was found in small amount.

On average, residential areas had range of helminth eggs between 4 to $254 \mathrm{eggs} / \mathrm{L}$. Student housing in Cisitu area had most number of helminth eggs with comparation to the others, followed by sample from Dago Atas and Bale Endah. Big variation come from non-residential septic tanks which were range between 14 to 617 eggs/L. Sample from post office in Cilaki area showed the most number of helminth eggs while middle industries in Kiaracondong was the lowest. Total amount of helminth eggs in septage per location of desludging can be seen in Figure 6.

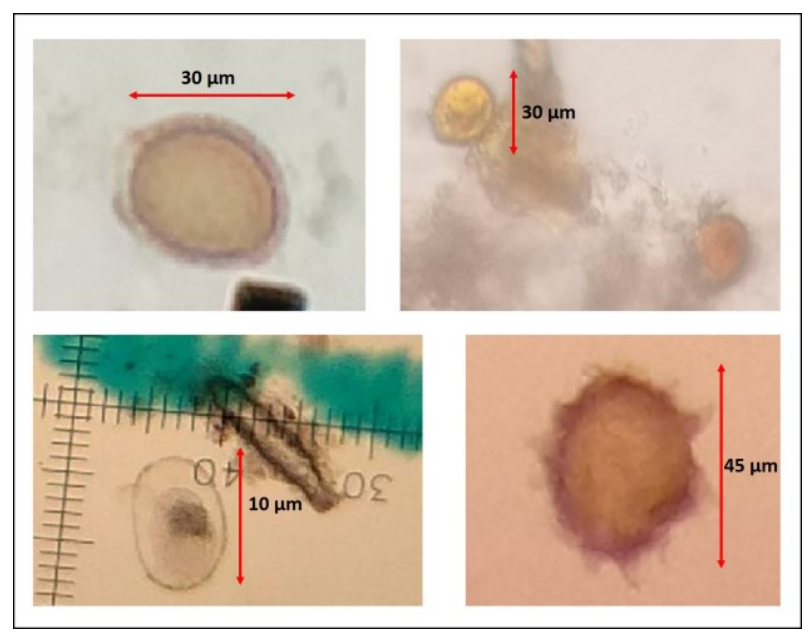

Fig. 4. Photomicrograph of some helminth eggs

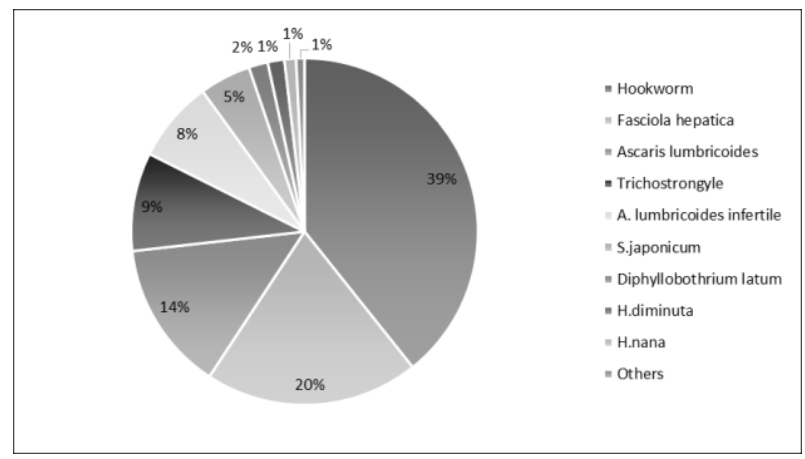

Fig. 5. Helminth eggs presence percentage

When examining prevalence by species, and when only STH were considered, hookworm was highest, followed Ascaris lumbricoides. Both of them were found in all samples. Based on septic tank place, hookworm highly found in Cilaki post office which is more like public toilet. The other highest souce location is Cisitu student housing, Biotech company and laboratory in Pasteur, and Dago Atas housing. For Ascaris lumbricoides highly found in Cilaki post office, Dago Atas housing, and Baleendah housing. Fasciola hepatica, trematode which is common parasitic disease in ruminants highly found in Biotech company and laboratory in Pasteur, and some hotels in Pasteur area.
We further analysis chemical parameter septage of 6 areas. The chemical parameter chosen is conductivity to determine the mineral value contained in the blackwater sample. High conductivity mean high mineral value. Total solid and BOD shows sludge and feces value in sample. $\mathrm{pH}$, orthophosphat, and nitrat shows biological process occures in septic tank before enter Bojongsoang sewage treatment plant. Table 1 shows result of chemical parameter examination

Table. 1. Chemical analysis of fecal sludge

\begin{tabular}{|l|c|r|r|r|}
\hline \multirow{2}{*}{$\begin{array}{c}\text { Parameter } \\
\text { analysis }\end{array}$} & \multirow{2}{*}{ Unit } & Cisitu & Cihampelas & $\begin{array}{c}\text { Tubagus } \\
\text { Ismail }\end{array}$ \\
\cline { 3 - 5 } & & & 1392 & 881 \\
\hline Conductivity & $\mu \mathrm{S} / \mathrm{cm}$ & 1012 & 1392 & 2700 \\
\hline Total solid & $\mathrm{mg} / \mathrm{l}$ & 5730 & 45470 & 7 \\
\hline pH & - & 6.75 & 6.93 & 21429 \\
\hline BOD & $\mathrm{mg} / \mathrm{l}$ & 15612 & 17449 & 18.2 \\
\hline Orthophosphat & $\mathrm{mg} / \mathrm{l}$ & 12.1 & 21.3 & 1.83 \\
\hline Nitrat & $\mathrm{mg} / \mathrm{l}$ & 5.41 & 1.46 & \\
\hline
\end{tabular}

\begin{tabular}{|l|c|r|r|r|}
\hline \multirow{2}{*}{$\begin{array}{c}\text { Parameter } \\
\text { analysis }\end{array}$} & \multirow{2}{*}{ Unit } & \multicolumn{3}{|c|}{ Result } \\
\cline { 3 - 5 } & & Cipedes & $\begin{array}{c}\text { Bale } \\
\text { Endah }\end{array}$ & Antapani \\
\hline Conductivity & $\mu \mathrm{S} / \mathrm{cm}$ & 602 & 1350 & 4330 \\
\hline Total solid & $\mathrm{mg} / \mathrm{l}$ & 1680 & 5050 & 5650 \\
\hline pH & - & 7.15 & 7.36 & 7.87 \\
\hline BOD & $\mathrm{mg} / \mathrm{l}$ & 23265 & 33673 & 21735 \\
\hline Orthophosphat & $\mathrm{mg} / \mathrm{l}$ & 2.34 & 30.8 & 19.9 \\
\hline Nitrat & $\mathrm{mg} / \mathrm{l}$ & 1.23 & 0.996 & 8.68 \\
\hline
\end{tabular}

This study explore the concentration and prevalence of helminth eggs in FS samples in an Indonesia urban area, Bandung city, West Java.Our previous study found that soil, water and vegetables in urban agriculture in Northern and Southern part of Bandung has contaminated with helminth eggs [6].

We recorded that hookworm found become the highest prevalence STH eggs in 17 samples from different sources. It followed by Ascaris lumbricoides. Based on guideline of helminthiasis prevention that is released by Indonesia Ministry of Health in 2017, Ascaris lumbricoides, hookworm (Necator americanus, Ancylostoma sp.) and Trichuris trichiura are the main STH that found and infective Indonesia people, especially children [5]. Beside it, some researchs showed that some helminth such as Ancylostoma duodenale and Trichostrongylus orientalis also strongly presence in feces and vegetable samples [10,11]. The type of food that people consumes also impact the helminth eggs species contained in the feces. In this study, we only found STHs Ascaris lumbricoides and hookworm dominant the sample with less than $1 \%$ prevalence of Trichuris trichiura. Even though some studies of helminthiasis prevalence of student around Bandung showed that Trichuris trichiura was including dominant species that is infected $[12,13]$. 


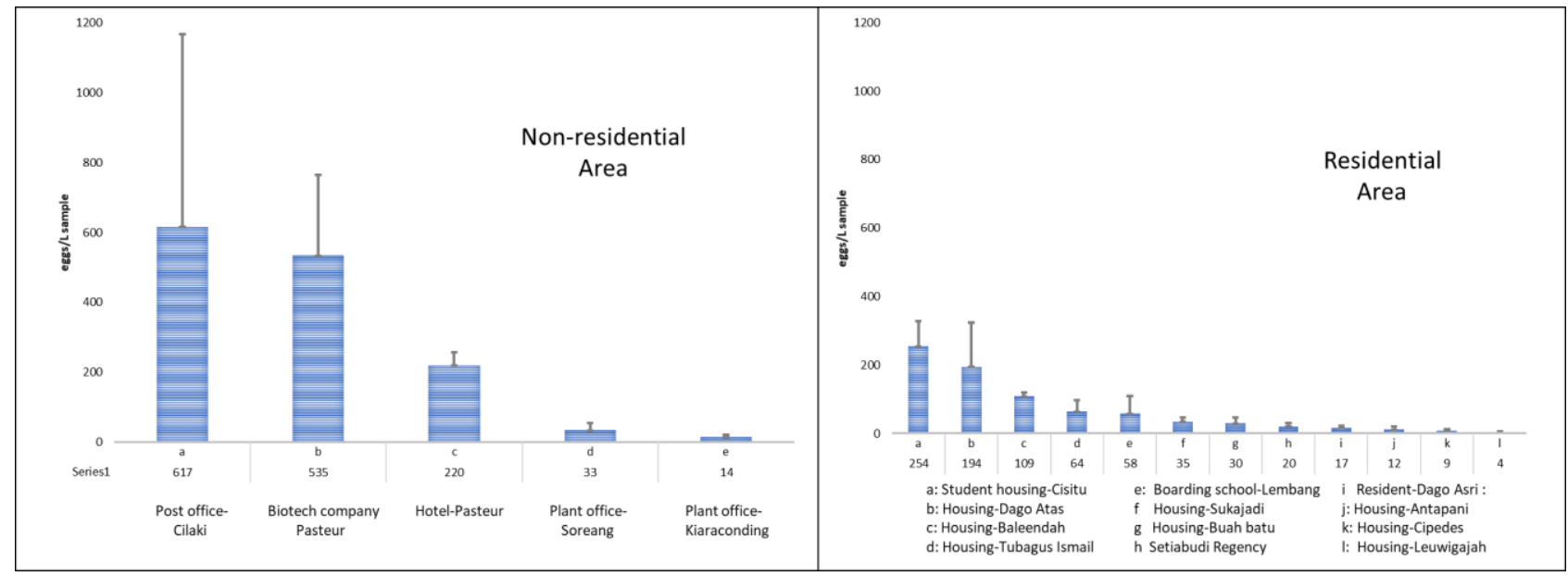

Fig. 6. Helminth eggs presence in several samples location

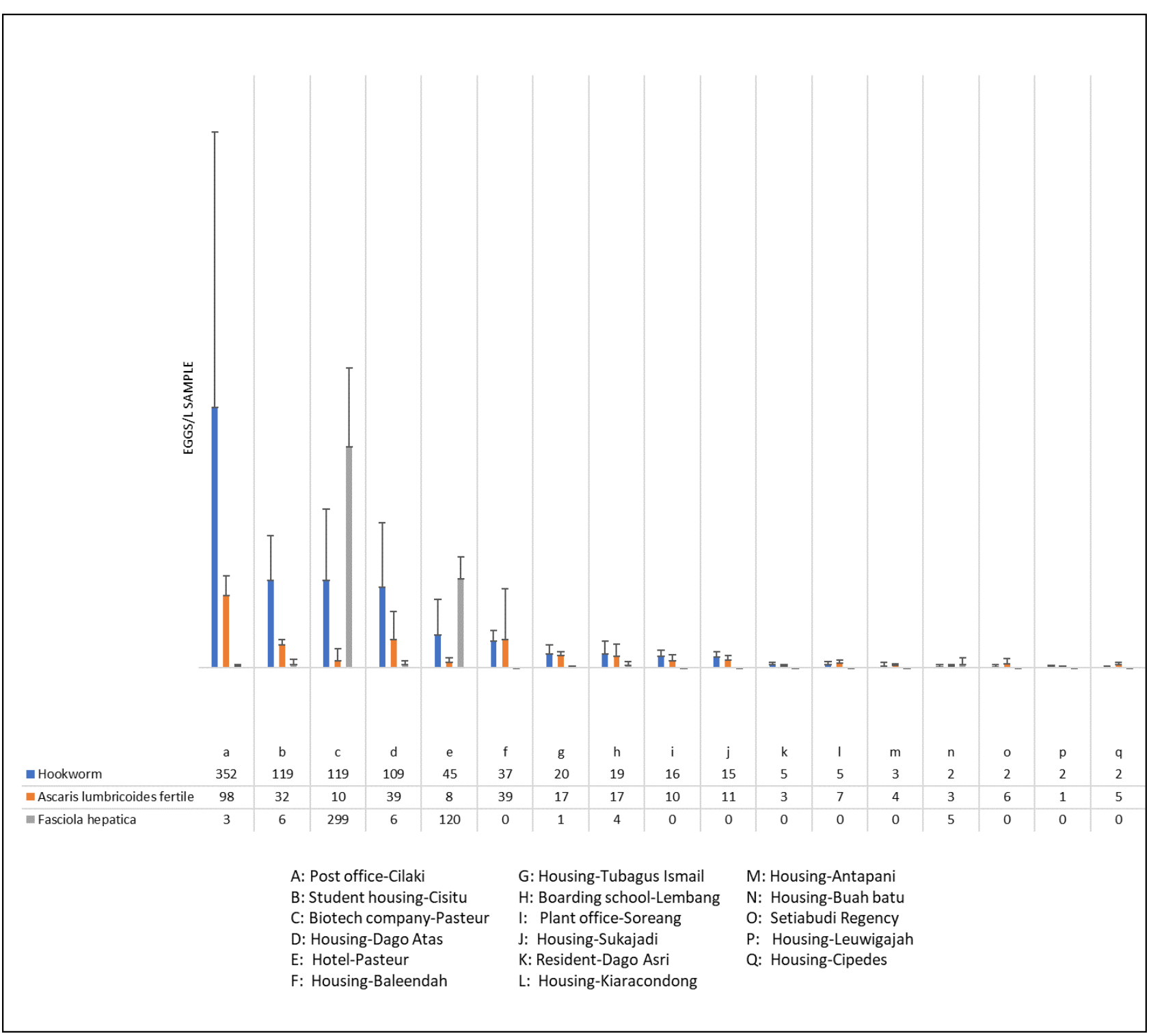

Fig. 7. Hookworm, Ascaris lumbricoides and Fasciola hepatica presence in 17 samples location 
Hookworm is acquired to people by walking barefoot or directly contact with soil contaminated with human or animal feces containing hookworm larvae which are the infective agents transmitted via the skin. There are some factors that influenced people especially children can infected by hookworm, that is poor sanitation, sanitation behaviour (including open defecation and handwash) and habits of playing on the ground (barefoot and handwash) [14]. Hookworm like moist and clay soil for growing. In Indonesia, there are many domestic animal like cat and dog without owner and can run wild around the place. Without owner, these hookworm infected animals can easily defecate in random area and spread the egg or larvae in the environment.

Ascaris lumbricoides high infection found among schoolchildren, as well. The family members infected by A. lumbricoides were a source of infection for transmitting the intestinal helminths in the community [15].

In general, hookworm and $A$. lumbricoides are the common STH that is found in country with bad habits of sanitation practice, such as open defecation and poor handwashing habits and lack of sanitation infrastructure. STH egg concentration in sludge from main wastewater treatment plants is mainly depends on their concentration in raw wastewater [16]. Helminth eggs is very resistant in the environment and their survival could reach six months to one year in soils [17].

The existence of STH egg species, hookworm and $A$. lumbricoides in all samples of this study which already had septic tank, show the magnitude of risk factors of Indonesian people related to helminthiasis. Unfortunately, this infection never found in list of twenty major disease which is released by Health Status report of primary health center and health institution of Bandung city. It means low awareness of helminth infection threat. While mortality is low, morbidity of helminthiasis is more dangerous. For year 2010, estimated globally, around 438.9 million people were infected with hookworm and 819.0 million with $A$. lumbricoides. Of these, 4.98 million years lived with disability (YLDs) attributable to STH, 65\% were related to hookworm and $22 \%$ to $A$. lumbricoides The vast majority of STH infections (67\%) and YLDs (68\%) occurred in Asia [18].

Fasciola hepatica commonly found in mammals and causes fasciolosis relating to the life cycle of the worm Fasciola sp. Mammals (livestock) infected by eating the forage contains metacercariae (Fasciola infective larvae) [19]. Ruminant livestock are often infected by Fasciola sp is cattle, goats, sheep and buffalo [20]. Manus and Dalton in 2006 estimate prevalence fasciolosis of livestock in Indonesia reaches 90\% [21].

Eight samples has recorded contain Fasciola hepatica. The highest prevalence came from Biotechnology company and laboratorium in Pasteur reach average $162 \mathrm{egg} / \mathrm{L}$ sample. It need confirmation for the high amount of these eggs in the septic tank. It could be coming from the testing animal that can be used for vaccine research and development. If it related to the animal, it was interesting that egg of this species also found in fecal sludge of hotel, office and resident area. Amount of F. Hepatica from sample of hotel that place in the same street with the Biotech company reach $50 \%$ of eggs. There is a possibility, presence of it in the resident area and public office toilet due to pet and domestic animal, such as dog and cat. Even, we cannot found any record or published data about F.hepatica infection in human in Indonesia, but in other countries, the number of reports of humans infected has increased significantly since 1980 [22]. Several geographical areas have been described as endemic for the disease in humans, with prevalence and incidence ranging from low to very high. The important point of the reference study showed that high prevalence in human does not seem to correlate with areas where fasciolis is a major veterinary problem, such as in Indonesia.

Variation in the concentration of helminth egg in residential samples showed that housing with better environmental sanitation and permanen resident had less prevalence compare to housing in densely populated area and tend to experient occupant changes, such as student housing. In non residential samples, high load of helminth eggs in Cilaki post office influenced by its position next to central office of governor. Visitors and street vendors, in weekday and weekend, can become users of the toilet that office had for public. Turn over of visitor and guest with different profile possible influenced the diversity and amount of helminth eggs in the FS sample.

Big variation of chemical parameter values between 6 different FS sources showed that there are some factors that influenced it. Different operators of desludging truck with variation of vacuum pump using on the truck, type of septage collection from the septic tank that could be supernatant rather than sedimented sludge. Beside that, different cleaning frequencies at the source could affect variability of chemical and biological parameter values. It also supported by statistical analysis with Spearman rank correlation that is used to determine the correlation between total concentration of helminth eggs and each chemical parameter (total solid, conductivity, $\mathrm{pH}, \mathrm{BOD}$, orthophosphate, and nitrate) in several FS source. The result show there is no correlation between the parameters with amount of helminth egg in sample. The analysis evinced that content of FS samples from septic tank is independent of the chemical parameter such as solid content, BOD, conductivity, and orthophosphate.

High helminth egg concentration in FS samples show that Bandung has high risk for parasite spreading, especially in the area with insufficient sanitation infrastructure. Unintentionally reuse of contaminated water in drainage, stream, by urban farmer for irrigation and urban dweller in dry season at some places as water source will increase the level of risk.

The result also showed that septic tank as common onsite sanitation in Indonesia is not efficient for removal helminth eggs. Removal rates that is reported for treatment system only refer to removal helminth eggs from suspension in the wastewater into sedimen or sludge, not about destruction or inactivation of the eggs [23]. So, advance treatment for FS is needed to achieve

\footnotetext{
*Corresponding author: mayrina@tl.itb.ac.id
} 
recommended quality criteria $\leq 1 \mathrm{egg} / \mathrm{L}$ by for public health protection especially for agriculture and aquaculture [24]. Desludging service become crucial to ensure further FS treatment instead of discharge to natural system. It also can be done by improving onsite sanitation. In addition, there is no guarantee that non detection of helminth egg confirm the effluent are free of parasites even after advance treatment system. Then, identification and enumeration of helminth eggs in water and wastewater would be considered in country with high prevalence of helminthiasis like Indonesia.

The authors express gratitude to the research fund granted by Research, Community Service and Innovation Program (Program Penelitian, Pengabdian kepada Masyarakat dan Inovasi, P3MI) from ITB.

\section{References}

1. L. Setyowatiningsih and S. Surati, JRK 6(1), 40-44 (2017).

2. Republic of Indonesia, Ministry of Health. 2015. National Health System. http://www.depkes.go.id. Accessed: 25 May 2017

3. Directorate General of Disease Control and Environmental Health. Profile of disease control and environmental health in 2008. Director General of Environmental Disease Control, 2009

4. WHO.https://www.who.int/gho/neglected_diseases/s oil transmitted helminthiases/en/. Accessed: August $18^{\text {th }} 2019$

5. Peraturan Menteri Kesehatan Republik Indonesia Nomor 15 tahun 2017 tentang Penanggulangan Cacingan.

6. M. Firdayati, P.A. Notodarmojo, B.S. Muntalif, D. Trihartomo, I.S. Fathuna, and K. Somantri, Indones. J. Urban. Environ. Technol. 2(1), 27-34 (2018)

7. R.G. Feachem, D.J. Bradley, H. Garelick, D.D. Mara, Sanitation and disease : health aspects of excreta and wastewater management (World Bank Studies in Water Supply and Sanitation, New York, 1983)

8. B.J. Llyod and G.I. Frederick, Wat Sci Tech 43, 375-386 (2000)

9. M.C.F. Rocha, M.E. Bares, and M.C.B. Braga, Water. Res 103, 245-255 (2016)

10. Arsanti et al., JMIK 9 (2011)

11. V. Asihka, Nurhayati, and Gayatri, JKA 3(3), 480485 (2014)

12. M.M. Silitonga, U. Sudharmono, M. Hutasoit.. http://journal.fk.unpad.ac.id/index.php/mkb/article/v iewFile/260/pdf_119. Accessed: September $8^{\text {th }} 2019$

13. D. N. Gloria. https://repository.maranatha.edu/17019/1/9910164 ABSTRACT toc.pdf.Accessed : September $8^{\text {th }} 2019$

14. D.Sumanto.Risk Factors of Hookworm Infection on Elementary School Student.Case study in Rejosari
Village, Karangawen, Demak.In Indonesian language. (Master thesis, UNDIP, 2010)

15. R. Subahar, P. Patiah, A. Widiastuti, and $H$. Wibowo, JPM 11(1), 16-25 (2017)

16. I.D. Amoah, P. Reddy, R. Seidu, and T.A. Stentrom, J. Enviro. Manage 206, 1020-1027 (2018)

17. P.G. Gaspard and J. Schwartzbrod, Int. J. Hyg. Envir. Heal 206, 117-122 (2003)

18. D.Humphries, S. Nguyen, S. Kumar, J. E. Quagraine, J. Otchere, L. M. Harrison, M. Wilson, and M. Cappello, Am J Trop Med Hyg. 96(2), 347-354(2017)

19. E. Martindah, S. Widjajanti, S.E. Estuningsih, Suhardono, Wartazoa 15 (2005)

20. Purwaningsih, Noviyanti, and R.P. Putra, Acta. Vet. Indones 5(2), 120-126 (2017)

21. M.D.P. Manus, and J.P. Dalton, Parasitology 133, 543-562 (2006)

22. M. Kaya, R. Beştaş and S. Çetin. World J Gastroenterol. 17(44), 4899-4904 (2011)

23. D.Mara. Handbook of Water and wastewater Microbiology

24. WHO (World Health Organization), WHO Guidelines for the Safe Use of Wastewater, Excreta and Greywater (WHO Press, 2006) 